\title{
BREVE HISTÓRICO DA OCUPAÇÃO PRÉ- HISTÓRICA DA REGIÃO NOROESTE DO ESTADO DE SÃO PAULO
}

\author{
Paula Cabral de Lima, Neide Barrocá Faccio \\ Universidade Estadual Paulista - UNESP, Curso de Geografia, Presidente Prudente, SP. E-mail: \\ paulacabral.I@hotmail.vom
}

\begin{abstract}
RESUMO
Nesse artigo procuramos discorrer brevemente sobre a ocupação indígena na região Noroeste do Estado de São Paulo. Para tanto foram feitos levantamento bibliográficos, com o intuito de desenvolver uma explanação sobre os grupos pré-coloniais que residiram na região antes da ocupação pela população brasileira atual. Dessa forma, o objetivo foi o de desenvolver um levantamento sobre o histórico de ocupação desses indígenas na região para compreender seus fluxos migratórios e possibilitar inferências e interpretações do modo de vida desses grupos. Acreditamos que o trabalho contribui com o conhecimento da dispersão desses grupos, pois reconhecemos que a Região é carente de pesquisas com esse enfoque.
\end{abstract}

Palavras - chave: Fluxos Migratórios, Histórico de ocupação, dispersão regional.

\section{BRIEF HISTORY OF THE PREHISTORIC OCCUPATION OF THE NORTHWEST REGION OF THE STATE OF SÃO PAULO}

\begin{abstract}
In this article we seek to briefly discuss the indigenous occupation in the Northwest region of the State of São Paulo. For this purpose, a bibliographical survey was carried out with the purpose of developing an explanation about the pre-colonial groups that lived in the region before the occupation by the current Brazilian population. Thus, the objective was to develop a survey of the history of occupation of these indigenous people in the region to understand their migratory flows and to allow inferences and interpretations of the way of life of these groups. We believe that the work contributes to the knowledge of the dispersion of these groups, since we recognize that the Region is lacking researches with this approach.

Keywords: Migration Flows, History of occupation, regional dispersion.
\end{abstract}




\section{INTRODUÇÃO}

Os grupos indígenas do Noroeste do Estado de São Paulo, segundo o Mapa Etno-Histórico de Nimuendaju, publicado pelo IBGE(1981) são caracterizados por Índios Kayapó, que fazem parte do tronco linguístico Jê e que possuem uma tradição cerâmica denominada de Aratu. (Figura 1).

A Tradição Aratu foi apresentada, pela primeira vez, no Relatório Anual do PRONAPA, em 1969/70, após a descoberta por Calderón, em 1968 de 24 sítios no Recôncavo Baiano. Calderon caracterizou a cerâmica e os padrões dos 24 sítios e os identificou como pertencentes a grupos semi-permanentes, coletores com uma agricultura incipiente (CALDERÓN,1969).

Figura 1. Fragmento do mapa Etno-histórico de Curt Nimuendaju com ênfase para a Região Noroeste do

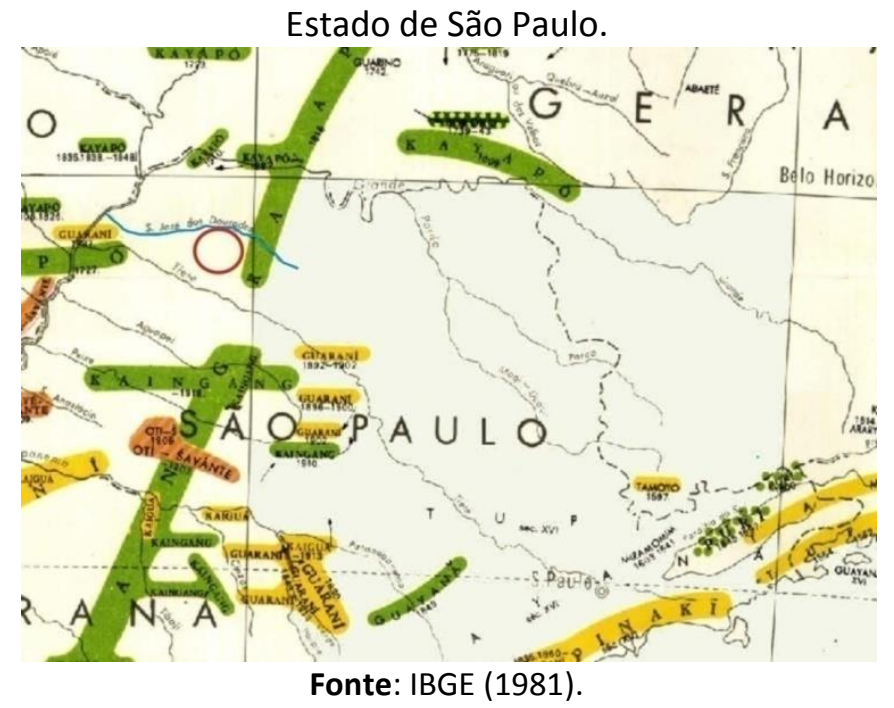

A Tradição Aratu está presente na Região Norte/Noroeste de São Paulo, Sul de Minas Gerais, Goiás e Espírito Santo e foi estudada anteriormente por Calderón (1969, 1971 e 1974) e Perota (1971 e 1974), autores que a definiram como tradição arqueológica em 1968 (Brochado et al, 1969) e, mais claramente, caracterizada na reunião final do PRONAPA (WASHINGTON apud SCHIMITZ et al, 1982), no ano de 1970.

\section{OBJETIVO E METODOLOGIA}

O trabalho objetivou desenvolver um reconhecimento a cerca dos grupos indígenas que habitaram a região Noroeste do Estado de São Paulo, para contribuir com as pesquisas sobre o Sistema de Ocupação dos Kayapó e de seus fluxos migratórios no território de São Paulo. Para o desenvolvimento desse trabalho foram feitos levantamentos bibliográficos utilizando relatos etnográficos, além de um levantamentos junto ao IPHAN, sobre as tradições ceramistas dos sítios arqueológicos encontrados na região Noroeste de São Paulo.

Esses levantamentos tiveram o intuito de identificar por meio da tradição cerâmica os possíveis grupos indígenas que passaram por essa paisagem e cruzar as informações encontradas nos relatos etno históricos feitos por viajantes no período de ocupação do território pela sociedade brasileira.

\section{RESULTADOS E DISCUSSÃO}

Os pesquisadores acreditam que os grupos que confeccionam a cerâmica da Tradição Aratu tenham origem em dois fluxos migratórios distintos. Um fluxo migratório ocupou todo o centro-sul do Estado de Goiás e estendeu-se em direção ao Vale do São Francisco produzindo a 
cerâmica denominada Aratu. Outro fluxo migratório saiu do Noroeste em direção ao Estado do Mato Grosso, produzindo a cerâmica denominada Uru (OLIVEIRA, 2005).

Os grupos indígenas que confeccionaram a cerâmica da Tradição Aratu tiveram diversas fases, possivelmente por ocuparem uma grande área e por sofrerem influências de outras tradições. Há sítios que pertence a mesma fase, no entanto, com predomínio de antiplásticos diferentes. Na sua Fase nômade, os grupos indígenas se localizavam em áreas extensas, dentro de micro regiões, principalmente no Mato Grosso, Goiás, Alta Araguaia Goiano, dentre outros. Estendiam-se por três grandes bacias hidrográficas: Araguaia, Parnaíba e Tocantins. Mesmo assim, nenhum sítio encontra-se próximo as bordas desses rios, mas sim de córregos de águas perenes e eventualmente rios. Os sítios situam-se nas colinas ou chapadas, utilizando para a construção da aldeia um declive suave em direção ao córrego. (SILVA; FACCIO, 2010 p.2,3).

Oliveira acredita que a ocupação desses grupos tenha causado mudanças significativas na paisagem dessas regiões. Por mais que os grupos fossem diferentes nas suas características culturas, "tinham na aldeia circular uma mesma estratégia de estruturação e organização da sociedade, que foi amplamente implantada na região" (OLIVEIRA, 2005, p. 23).

Os Kayapó normalmente organizam suas aldeias com a mesma configuração dos grupos pertencentes ao tronco Jê, em forma circular, oval ou em ferradura (OLIVEIRA, 2005). Segundo WUST (1983), as aldeias da Tradição Aratu podiam alcançar mais de 400 metros de diâmetro, ter dois a três anéis concêntricos e abrigar mais de dois mil indivíduos.

Antes de a interação hostil com a sociedade brasileira e a correlata intensificação dos ataques entre as comunidades kayapó assumirem o papel importante que passaram a ter, a organização e cultura kayapó baseavam-se num sistema de comunidades grandes que eram totalmente auto-suficientes e autónomas. A organização dessas grandes aldeias pode ser resumidamente descrita como segue. Todas as aldeias kayapó eram organizadas como grandes círculos ou casas de famílias extensas em torno de uma praça central, onde havia uma casa dos homens. As aldeias maiores do passado possuíam duas casas dos homens, uma na parte leste e a outra na parte oeste da praça e até três círculos concêntricos de casas. A maioria das aldeias atuais mantém a forma circular. (TURNER, 1995 p. 317).

De acordo com Turner, "o nome "Kayapó" é de origem tupi (significa literalmente "como macaco"). O nome que os Kayapó dão a si mesmos é "Mebengokre", que significa literalmente "gente do espaço dentro da(s), ou entre a(s) água(s)" (TURNER, 1991). Chama atenção essa autodenominação, principalmente, porque os sítios identificados na região estudada foram encontrados próximos a cursos d'água pequenos e com distâncias curtas de rios maiores (no caso é o Rio São José dos Dourados). "As aldeias são geralmente construídas junto de um rio ou riacho, de preferência rico em peixes; a distância até o riacho mais próximo nunca é, de qualquer modo, grande". (TURNER, 1995, p. 317). 
Foto 1. Aldeia Kaiapó nas Margens do Rio Xingu

Fonte: Mittermeier (2016)

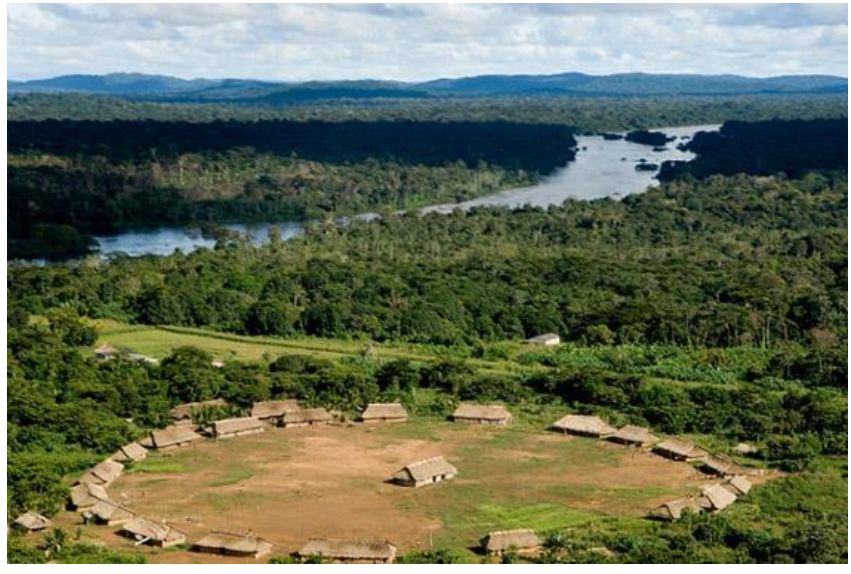

De acordo com Oliveira e Viana (2000), os grupos que produziram a cerâmica da Tradição Aratu penetraram na região (afluentes do Rio Paranaíba e do Araguaia) por volta do século IX d. C., entrando em colapso antes do início da Conquista Ibérica. Turner acredita que a palavra tupi "Kayapó" refere-se aos Kayapó meridionais que habitavam o Norte do Mato Grosso entre Cuiabá e o Xingu e que a diferenciação dos povos Jê se deu na área dos Rios Araguaia e Tocantins.

A cerâmica Aratu apresenta vasilhas simples, produzidas com antiplástico mineral, com formas esféricas e ovóides e geralmente, não são associadas à transformação da mandioca tóxica em alimento humano (WUST, 1983). As ocupações da Tradição Aratu no Estado do Espírito Santo são datadas de 838 e 1780 A.P $P^{1}$. Já na região norte de São Paulo de 426 +/- 152 A.P (ALVES; MACHADO, 1995) (Figura 2).

Não há muitos relatos de grupos da Tradição Tupiguarani ${ }^{2}$ na região norte do Estado de São Paulo. Contudo a análise do material encontrado nos Sítios Abelha, Dourado e Lajeado nos leva a acreditar que indivíduos dessa tradição tiveram algum tipo de contato com o grupo Kayapó dos sítios aqui estudados (Figura $\mathbf{3}$ ).

Figura 2. Sítios Arqueológicos associados à Tradição Aratu no Norte do estado de São Paulo

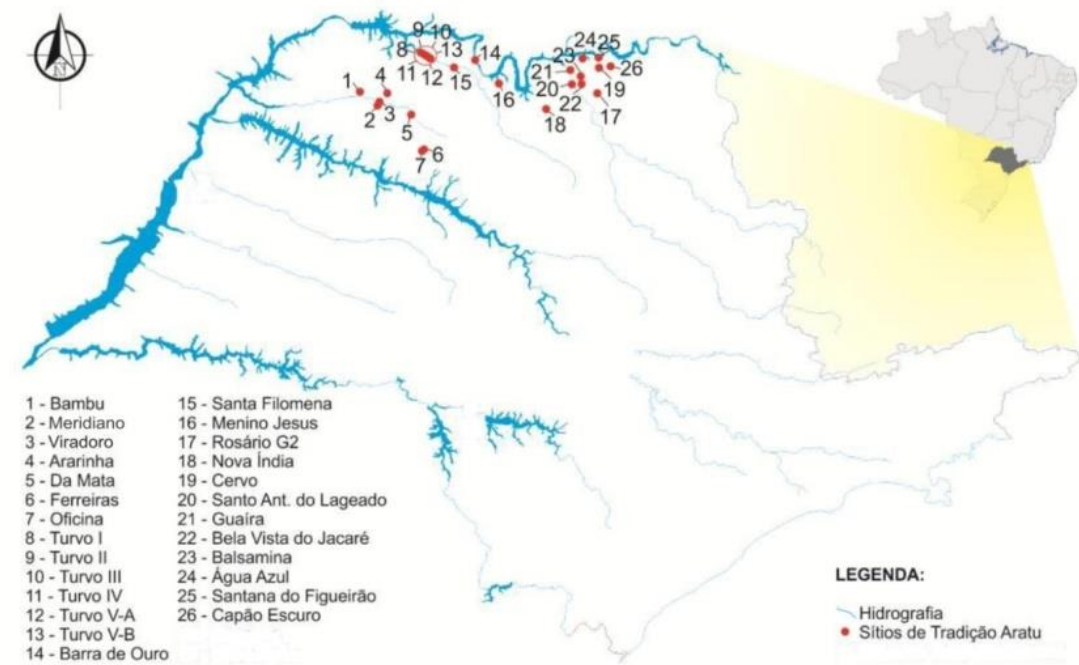

Fonte: Faccio et al. (2014)

\footnotetext{
${ }^{1}$ Antes do Presente

${ }^{2}$ Quando nos referimos a tradição ceramista convencionou-se escrever a palavra Tupiguarani tudo junto para diferenciar do tronco linguístico que se escreve Tupi-Guarani.
} 
Figura 3. Localização aproximada dos principais grupos de falantes de línguas Tupi-guarani na época do contato

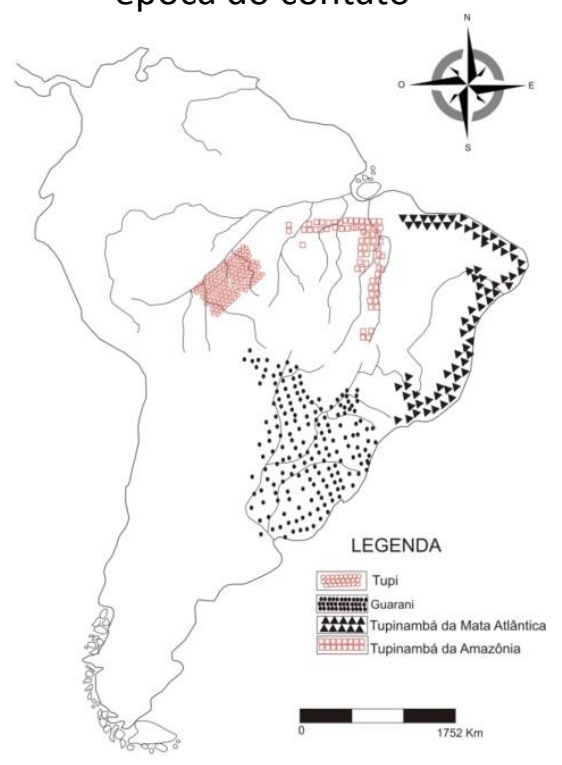

Fonte: Adaptado de Almeida e Neves (2015).

O sistema e ocupação índigena Tupi-Guarani do Estado de São Paulo foi desmantelado pelas várias frentes de invasão ibérica, a partir do século XVI (MORAIS, 2003).

A cerâmica da Tradição Tupiguarani é um elemento característico desses grupos segundo estudiosos desse assunto.

Os atributos politéticos da cerâmica da Tradição Tupi-Guarani são o uso de antiplástico de caco moído e/ou mineral, a presença de vasos compostos (um ângulo na parede) ou complexos (dois ou mais ângulos nas paredes), com base convexa ou ovalada (com exceção dos grandes pratos planos para assar mandioca), vasilhas com decorações plásticas corrugadas, unguladas, digitadas, raspadas, escovadas, decorações estas quase sempre encontradas no exterior do vaso, assim como decorações pintadas em vermelho, preto e branco, que aparecem como banhos, faixas e/ou motivos geométricos, dentro ou fora dos vasos. Urnas funerárias também são comuns e, em geral, consistem na reutilização de uma grande panela (muitas vezes corrugada) coberta por uma tampa, vasos relacionados ao preparo e ao consumo de bebidas alcoólicas (Brochado 1984; Buarque 2010; La Salvia\& Brochado 1989; Noelli \& Brochado 1998). (ALMEIDA; NEVES, 2015 p. 501).

A cerâmica Tupiguarani é encontrada em abundância ao longo de todo o Rio Paranapanema, no Rio Paraná e de seus afluentes em área de alta ou média vertente e, mais raramente, em terraços fluviais (FACCIO, 2000). As vasilhas são feitas por meio de cordéis superpostos em espiral, da base em direção a borda e depois alisados e preparados, as peças em miniatura são feitas inteiriças por meio de modelagem (FACCIO, 2000).

A quantidade de peças decoradas varia de uma região para outra e de um sítio para outro e estão ligadas diretamente com o tamanho do sítio, a densidade populacional e as práticas cotidianas desenvolvidas. A cultura material da Tradição Tupiguarani é composta também por pedras polidas e pedras lascadas.

Cada grupo étnico pré-colonial, da sua maneira desenvolveu uma cultura, na esfera material e imaterial, adaptada às necessidades de sobrevivência. As populações pré-coloniais dispunham de poucos avanços tecnológicos, dependiam quase que exclusivamente das condições 
ambientais para a sobrevivência. Nesse sentido, é possível que as populações tenham desenvolvido compartimentos na sua cultura que oferecessem respaldo ao ambiente eleito como ideal ou não, seguindo pressupostos culturais.

\section{CONCLUSÃO}

As línguas pertencentes ao tronco Tupi-Guarani eram predominantes entre os índios pré coloniais, isso talvez explique a forte influência por parte desses índios por todo Brasil. Nossas heranças indígenas provêm, em sua maior parte, dos tupis e dos guarani.

Os índios da Tradição Tupiguarani usavam a cerâmica para diversas atividades como para acondicionar água, grãos, bebidas alcoólicas feitas especialmente para festividades e rituais, além de utilizar os maiores vasos cerâmicos como urnas funerárias. Normalmente a cerâmica Tupiguarani é marcada por decorações simétricas de motivos diversos tendo uma característica extremamente artística, as mulheres tinham um papel de destaque na confecção dessas vasilhas e as relações de parentesco estavam, em grande parte, centradas nelas. Os povos da Tradição TupiGuarani influenciaram, de forma decisiva, a cultura brasileira, por meio de alimentos, palavras e costumes que ainda hoje são utilizados em muitos lugares do Brasil.

Diferentemente da Tradição Tupiguarani a Aratu caracteriza-se por materiais cerâmicos sem decorações e somente alisadas nas faces internas e externas, isso se dá, pois os grupos que desenvolviam esse tipo de cerâmica como os índios Kayapó, não transmitiam para a cerâmica seus rituais artístico e sim para seus próprios corpos que eram enfeitados com pinturas elaboradas, penas e adornos (cocares e mascaras feitas com fibras vegetais), esse é um dos motivos pelo qual os sítios arqueológicos Aratu não possuem muitos vestígios arqueológicos além da cerâmica simples, pois, os adornos eram feitos de materiais de rápida decomposição.

A cosmologia, vida ritual e organização social dos Kayapó, são extremamente ricas e complexas até hoje. Assim como são intensas e ambivalentes as relações com a sociedade nacional e com ambientalistas do mundo todo.

Nessa perspectivas acreditamos que a região Noroeste do Estado de São Paulo foi rota desses dois grupos (Kayapó e Tupi-Guarani) em determinado período não é possível ainda saber qual grupo esteve primeiro na região pois os materiais arqueológicos encontrados nos sítios estudados dessa região, apresentam influência das duas tradições cerâmicas. Contudo, esse levantamento mostra que por mais que os relatos etnográficos não apresentem relatos de grupos Tupi-Guarani na região os materiais arqueológicos demonstram que em algum momento houve contato de grupos Tupi-Guarani e Aratu- Sapucaí ou relações de troca de materiais cerâmicos e líticos polidos.

\section{REFERÊNCIAS}

ALMEIDA .F O e NEVES,E.G . Evidencias arqueológicas para a origem dos Tupis-guaranis no Leste da Amazônia. Revista Mana Vol. 21, n.3, P..449-525, 2015.

ALVES, M.A.MACHADO, L.C., Estruturas arqueológicas e padrões de sepultamento do Sítio Água Limpa, Monte Alto, SP. Coleção Arqueológica. Porto Alegre, EDIPUCRS, 1(2):295-319. 1995

BROCHADO J. P., CALDERÓN, V., CHMYZ, I., DIAS, O. F., EVANS, C., MARANCA, S., MEGGERS, B. J., MILlER, E. T., NÁSSER, N., PEROTA, C., PIAZZA, W., RAUTH, J. W., SIMÕES, M. Arqueologia brasileira em 1968: um relatório preliminar sobre o Programa Nacional de Pesquisas Arqueológicas. Publicações Avulsas do Museu Paraense Emílio Goeldi, nO 12. Belém: MPEG, 1969.

CALDERÓN, V. Contribuição ao conhecimento da arqueologia do recôncavo sul do Estado da Bahia. Programa Nacional de Pesquisa Arqueológicas (PRONAPA) Pronapa, v 5,p1969. 
FACCIO.N,B. Ocupações guarani na bacia inferior do rio Paranapanema, lado paulista: mesorregião da Capivara. In: II Semana da Geografia, 2000, Presidente Prudente, SP. Anais da II Semana da Geografia. Presidente Prudente, SP: FCT-Unesp, 2000. p. 32-35.

FACCIO,N.B; COSTA; LUZ,J.A.R; BARROCÁ,D; MATHEUS,E.P• Vasilhas duplas Aratu (macro-jê). Revista Ágora, Vitória, n. 20, 2014, p. 6-23

IBGE. Mapa etno-histórico de Curt Nimuendaju . Rio de Janeiro, Fundação Nacional Pró-Memória; IBGE, 1981 p. 69-91.

MITTERMEIER,C. Foto aldeia Kayaoó no Xingú. In: http://conservationphotographers.org/ . Acesso: 03 de outubro de 2016.

MORAIS O. Engenho São Jorge dos Erasmos na Perspectiva Arqueológica e Ambiental da Baixada Santista. RelatórioTécnico, 2003.

OLIVEIRA, E.R. Aspectos da interação cultural entre os grupos ceramistas pré-coloniais do médio curso do rio Tocantis. MAE-USP, 2005

OLIVEIRA, J.E;.VIANA, S.A. O Centro-Oeste antes de Cabral. Revista USP - Arqueologia Brasileira I, São Paulo, 44 (1): 142-189.2000

SCHMITZ, P.I: WUST, I . COPÉ, S.M. e THIES,U.M.E. Arqueologia do centro-sul de Goiás.Uma fronteira de horticultores indígenas no centro do Brasil. Pesquisa (Antropologia), São Leopoldo: Revista Instituto Anchietano de Pesquisa, n 22, 1982.

SILVA, L.J; FACCIO, N.B. O estudo da variabilidade cerâmica do Sítio Arqueológico Turvo III, FCT/UNESP, 2010.

TURNER, T. Os Mebengokre Kayapó: história, consciência social e mudança social das comunidades autônomas do sistema inter-étnica. Manuscrito não publicado. Departamento de Antropologia. Universidade de Chicago, 1991. 337pp

. Social body and embodied subject: bodiliness, subjectivity, and sociality among the Kayapo. Cultural Anthropology, v. 10, n. 2, 1995.

WÜST,I . Aspestos da ocupação Pré Colonial em uma área do Mato grosso de Goias- Tentaviva de Análise Espacial, USP. São Paulo 1983. 